\title{
Gastroenteroloji Kliniğine Başvuran Akut Üst Gastrointestinal Sistem Kanamalı Hastaların Retrospektif Değerlendirilmesi
}

\author{
Muhammed Fatih SAĞIROĞLU ${ }^{1}$, Murat ÇALAPKULU ${ }^{2}$, Macit GÜLTEN ${ }^{3}$ \\ 1 Başkent Üniversitesi Tıp Fakültesi, Tıbbi Onkoloji Bilim Dalı, Ankara. \\ 2 Sağlık Bilimleri Üniversitesi, Dışkapı Yıldırım Beyazıt Eğitim Araştırma Hastanesi, Endokrinoloji ve Meta- \\ bolizma Kliniği, Ankara. \\ 3 Bursa Uludağ Üniversitesi Tıp Fakültesi, İç Hastalıkları Anabilim Dalı, Gastroenteroloji Bilim Dalı, Bursa.
}

\section{ÖZET}

Üst gastrointestinal sistem (GİS) kanaması mortalite ve morbidite oranı oldukça yüksek olan acil bir durumdur. Bu çalışmamızda hastanemize üst GİS kanaması ile başvuran hastaların demografik özellikleri, klinik bulguları, başvuru şikayetleri, hemodinamik bulguları, komorbid hastalıkları, ilaç kullanım öyküleri, endoskopik bulguları, eritrosit süspansiyon (ES) replasman sayıları, yatış günleri ile ilgili güncel veri elde etmek ve literatürle karșılaştırmak amaçlanmıştır. Bu çalışma Ocak 2012-Aralık 2017 tarihleri arasında Bursa Uludağ Üniversitesi Tıp Fakültesi Gastroenteroloji Bölümüne başvuran endoskopi yapılan ve üst GíS kanama tanısı konulan 300 hasta üzerinde retrospektif olarak yapıldı. Hastaların dosyaları hastane arşivinden tarandı. Hastaların yaş ortalaması $61,80 \pm 17,18$ olarak saptandı. Hastaların \%63'ü erkek \%37'si kadındı. Hastaların en ssk bașvuru nedeni \%37 ile melena olarak saptandı. Hastaların \%84,3'üne eşlik eden komorbid bir hastalık vardı. En sık komorbid hastalık \%42,7 ile hipertansiyondu. Hastaları \%51,3’ü kanamaya yatkınlık yaratan bir ve daha fazla ilaç kullanmaktaydı, bu ilaçlardan nonsteroid antiinflamatuar ilaçlar (NSAiIi) ve asetil salisilik asit (ASA) kullanımı belirgin şekilde fazla olduğu saptandı. Hastaların \%43,4'ünde peptik ülser (\%24,7'sinde duodenal ülser; \%18,7'sinde mide ülseri), \%28'inde gastroözofagial varis kanaması, \%9'unda gastrit (eritematöz/eroziv), \%7,7'sinde özofajit/özofagus ülseri, \%5,7'sinde malign ülser-kitle saptandı. Duodenal ülser erkeklerde daha sık saptandı. Sonuç olarak çalışmamızda üst GíS kanamasının en sık nedeni olarak peptik ülser kanaması saptandı. Özellikle ileri yaş, erkek cinsiyet, ASA ve NSAIİ kullanımı üst GíS kanamasında artmış bir risk faktörü olarak saptandı.

Anahtar Kelimeler: Üst gastrointestinal sistem kanaması. Etiyoloji. Peptik ülser. Endoskopi. Varis kanaması.

Retrospective Evaluation of Acute Upper Gastrointestinal System Bleeding Patients Admitted to Gastroenterology Clinic

\begin{abstract}
Upper gastrointestinal system (GIS) bleeding is an emergency with a high mortality and morbidity rate. In this study, it was aimed to obtain current data on demographic features, clinical findings, application complaints, hemodynamic findings, comorbid diseases, drug use histories, endoscopic findings, ES replacement numbers, hospitalization days of patients admitted to our hospital with upper GIS bleeding. This study was performed retrospectively on 300 patients who were admitted to Bursa Uludağ University Faculty of Medicine Gastroenterology Department between January 2012 and December 2017 and diagnosed with upper GIS bleeding. Patients' files were scanned from the hospital archive. The mean age of the patients was 61.80 ( \pm 17.18$) .63 \%$ of the patients were male, and $37 \%$ were female. The most common reason for admission was melena, with $37 \%$. There was a comorbid disease accompanying $84.3 \%$ of the patients. The most common comorbid disease was hypertension, with $42.7 \%$. $51.3 \%$ of the patients were using one or more drugs that were prone to bleeding, and nonsteroidal anti-inflammatory drugs (NSAIDs) and acetylsalicylic acid (ASA) were found to be significantly higher. Peptic ulcer in $43.4 \%$ of patients (duodenal ulcer in 24.7\%; gastric ulcer in 18.7\%), gastroesophageal varicose veins bleeding in 28\%, gastritis (erythematous / erosive) in $9 \%$, Esophagitis / esophageal ulcer in 7.7\% and 5.7\% had malignant ulcer-mass. Duodenal ulcer was most common in men. As a result, acute upper GIS bleeding is one of the most important emergency application reasons, and it can be fatal if not intervened in time despite the technological developments. In our study, peptic ulcer bleeding was found to be the most common cause of upper GIS bleeding. Especially, advanced age, male gender, ASA, and NSAID use were detected as an increased risk factor in upper GI bleeding.
\end{abstract}

Key Words: Upper gastrointestinal system bleeding. Etiology. Peptic ulcer. Endoscopy. Varicose veins bleeding.

Geliş Tarihi: 05.Haziran.2020

Kabul Tarihi:10.Kasım.2020

Dr. Muhammed Fatih SAĞIROĞLU

Başkent Üniversitesi Tıp Fakültesi,

Tıbbi Onkoloji Bilim Dalı,

Ankara.

Tel:: $03122036868 / 2729$

E-posta: dr.mfsagiroglu@gmail.com
Yazarların ORCID ID Bilgisi:

Muhammed Fatih SAĞIROĞLU: 0000-0002-3253-6112

Murat CALAPKULU: 0000-0002-7445-2275

Macit GÜLTEN: 0000-0002-4186-0731 
Üst gastrointestinal sistem (GİS) kanamaları; üst özofagus sfinkterinden treitz ligamentine kadar olan lümen içine kanamaları ifade etmektedir. Üst GİS kanama insidans1 100.000'de 103-172 vaka/y1l ve mortalite oranları \%2-10 arasında değişmektedir. Akut üst GİS kanaması erkeklerde kadınlardan daha sık görülmekte ve prevalansı yaşla birlikte artış göstermekte$\operatorname{dir}^{1}$.

Üst GİS kanamalarının büyük çoğunluğunu varis dış1 kanamalar oluşturmaktadır. Üst GİS kanama nedenleri sırasıyla peptik ülser, gastroözofagial varis kanamaları, özofajit, gastrit, üst GISS malignitesi, Mallory-Weiss sendromu olarak sayılabilir. Üst GİS kanama tanısı ile takip edilen bazı hastalarda ise kanama odağ teknolojik görüntülemelere rağmen saptanamayabilir ${ }^{2}$. Peptik ülser hastalığının en sık saptanan risk faktörleri Helicobacter Pylori (HP) enfeksiyonu ve ilaç kullanımıdır. Kanamaya yol açan ilaçlar arasında nonsteroid antiinflamatuar ilaçlar (NSAIII), asetil salisilik asit (ASA), diğer antiagregan ilaçlar, oral antikoagulanlar ve steroidler bulunur ${ }^{3}$.

Üst GİS kanamasında kullanılan spesifik tedaviler medikal, endoskopik, anjiografik ve cerrahi tedavi olarak sayılabilir. Medikal tedavi seçenekleri arasında ise $\mathrm{H} 2$ reseptör blokerleri (H2RB), proton pompa inhibitörleri (PPİ), vazopressin analogları, somatostatin ve analogları bulunur. Varis kanamalarında tedavi, medikal ve endoskopik (band ligasyon, skleroterapi) tedavi uygulamalarının bir kombinasyonundan oluşur, ${ }^{4,5}$.

Bu çalışmada hastanemize başvuran üst GİS kanamalı hastaların demografik verilerini, başvuru şikayetlerini, komorbid durumlarını, kanamaya eğilim yaratan ilaç kullanımlarını, başvuru anındaki vital değerlerini, endoskopik tanılarını, ES replasman sayılarını, yatış günlerini ve mortalite oranlarını saptamayı amaçladık.

\section{Gereç ve Yöntem}

Çalışmamıza fakültemiz Etik Kurulu'nun 20 Şubat 2018 tarih ve 2018-4/26 nolu etik kurul karar1 ile başlanmıştır. Çalışmamız Bursa Uludağ Üniversitesi Tıp Fakültesi Hastanesi Gastroenteroloji Bilim Dalında retrospektif olarak yapılmış olup, çalışmamıza Ocak 2012- Aralık 2017 yılları arasında özefagogastroduedonoskopi (ÖGD) ile üst GİS kanaması olduğu doğrulanan, 18 yaş ve üzeri olan hastalar dahil edildi. ÖGD yapılmayanlar veya yapılan ÖGD sonucu kanama odağı üst GİS kaynaklı olmayanlar, travmalı hastalar, gebeler ve verileri eksik olan olgular çalışma dışı bırakıld1. Bu kriterleri tam olarak sağlayan toplam 300 olgu çalışmaya alındı. Araştırma kapsamına alınan hastaların dosyaları arşivden tarand. Dosyalar incelenerek hastaların cinsiyeti, yaşı, başvuru şikâyeti, ek hastalık varlığı, kanamaya yatkınlık yaratan ilaç kullanım öyküsü (NSAİI, aspirin, steroid, antikoagulan, klopidogrel gibi), önceden geçirilmiş GİS kanama öyküsü, başvuru anındaki vital bulguları (arteriyel tansiyon, nabız), başvuru anındaki serum hemoglobin ve hematokrit değerleri, ÖGD yapılma zamanı (ilk 24 saat içerisinde veya ilk 24 saatten sonra), endoskopik bulguları, yapılan transfüzyon sayısı, hastanede yatış süresi, taburculuk durumu ve mortalite oranları incelendi.

\section{Istatiksel analiz}

Tüm veriler bilgisayar ortamına aktarılarak istatistiksel analizler için üniversitemiz network ağından ulaş1labilen SPSS for Windows, versiyon 23 (IBM Corporation, New York, United States) uygulamaistatistiksel analiz programı kullanılarak analiz edildi. Verilerin normal dağılım gösterip göstermediği Kolmogorov Smirnov testi ile incelenmiştir. Betimleyici değerler olarak sürekli değişkenler için verilerin dağ1lım yapısına göre ortalama (+/- standart sapma) ya da median (min-max), kategorik değişkenler içinse sayı (n) ve yüzde (\%) değeri verildi.

\section{Bulgular}

$\mathrm{Bu}$ çalışmaya üst GİS kanama tanısıyla merkezimize başvuran ve tedavi edilen toplam 300 hasta alındı. Hastaların demografik ve klinik verileri Tablo-I'de özetlenmiştir. Olguların \%63’ü (n:189) erkek ve \%37'si (n:111) kadındır. Hastaların ortalama yaş1 $61,80 \pm 17,18$ iken erkek olguların ortalama yaş1 $59,11 \pm 16,43$, kadın olguların ortalama yaşı $65,82 \pm 17,69$ bulundu.

Hastaların başvuru şikâyetleri değerlendirildiğinde, en sık başvuru nedeni olarak melena saptandi. Hastalarin \%37'sinin (n:111) melena, \%29'unun (n:87) hematamez ve melena, \%28,7'sinin (n:86) hematamez, \%3,3’ünün (n:10) hematokezya, \%2'sinin (n:6) ise sadece baş dönmesi şikâyeti ile hastaneye başvurduğu saptand1.

Hastalar kanama riskini arttıran ilaç kullanımları açısından değerlendirildiğinde ise toplam 300 hastadan \%23,3'ünün (n:70) ASA，\%22,3’ünün (n:67) NSAIII, \%10'unun (n:30) antikoagulan, \%7,3’ünün (n:22) klopidgrel, \%1'inin (n:3) steroid kullandığ saptandi.

Komorbid hastalıklar yönünden değerlendirildiğine sırasıyla hastaların \%42,7'sinde (n:128) hipertansiyon, \%26'sinda (n:78) karaciğer hastal1ğ1, \%23,7'sinde (n:71) kardiyak hastalık, \%22,7'sinde (n:68) diyabet, \%17,7'sinde (n:53) malignite, \%9'unda (n:27) nörolojik hastalık, \%6'sında (n:18) renal hastalık, \%4,7'sinde (n:14) hematolojik hastalık, \%4'ünde (n:12) solunum yolu hastal1ğ $, \quad \% 3,7$ 'sinde (n:11) romatolojik hastalık ve \%2,3'ünde (n:7) tiroid hastalı̆̆ saptand1. 


\section{Üst Gastrointestinal Sistem Kanaması}

Tablo I. Üst gastrointestinal sistem kanaması olan hastaların demografik ve klinik verileri

\begin{tabular}{|c|c|}
\hline Değişkenler & Sayı \\
\hline Toplam vaka & 300 \\
\hline Erkek (\%) & $189(\% 63)$ \\
\hline Kadın (\%) & $111(\% 37)$ \\
\hline Yaş ortalaması & $61,80 \pm 17,18$ \\
\hline Erkek & $59,11 \pm 16,43$ \\
\hline Kadın & $65,82 \pm 17,69$ \\
\hline \multicolumn{2}{|l|}{ Yaş Grupları } \\
\hline $18-59$ & $114(\% 38)$ \\
\hline $60-79$ & $138(\% 46)$ \\
\hline$\geq 80$ & $48(\% 16)$ \\
\hline \multicolumn{2}{|l|}{ Vital Bulgular ve Hemogram } \\
\hline Nabız (dk) & $88 \pm 17,7$ \\
\hline Sistolik Kan Basıncı (mmHg) & $110 \pm 23,0$ \\
\hline Diyastolik Kan Basıncı (mmHg) & $65,5 \pm 12,3$ \\
\hline Hemoglobin (gr/dl) & $9,4 \pm 2,5$ \\
\hline Hematokrit (\%) & $28,5 \pm 7,4$ \\
\hline \multicolumn{2}{|l|}{ Başvuru Şikâyeti } \\
\hline Melena & $111(\% 37)$ \\
\hline Hematemez+Melena & $87(\% 29)$ \\
\hline Hematamez & $86(\% 28,7)$ \\
\hline Hematokezya & $10(\% 3,3)$ \\
\hline Baş Dönmesi, Bayılma Hissi & $6(\% 2)$ \\
\hline \multicolumn{2}{|l|}{ Ek Hastalık } \\
\hline Hipertansiyon & $128(\% 42,7)$ \\
\hline Karaciğer hastalık & $78(\% 26)$ \\
\hline Kardiyak hastalık & $71(\% 23,7)$ \\
\hline Diyabet & $68(\% 22,7)$ \\
\hline Malignite & $53(\% 17,7)$ \\
\hline \multicolumn{2}{|l|}{ İlaç Kullanımı } \\
\hline ASA & $70(\% 23,3)$ \\
\hline NSAil & $67(\% 22,3)$ \\
\hline Antikoagulan & $30(\% 10)$ \\
\hline Klopidgrel & $22(\% 7,3)$ \\
\hline Steroid & $3(\% 1)$ \\
\hline
\end{tabular}

NSAIII: Nonsteroid antiinflamatuar ilaçlar; ASA: Asetil salisilik asit

Olguların endoskopi yapılma zamanları değerlendirildiğinde \%68,3'üne (n:205) ilk 24 saatte, \%31,7'sine (n:95) 24 saat geçtikten sonra endoskopi yapıldığı saptandı. Hastaların \%35,7'sinde (n:107) daha önce tanısı konulmuş bir GİS kanama öyküsü mevcut iken, \%64,3'ünde (n:193) herhangi bir GíS kanama öyküsü bulunmamaktaydı.

Hastaların başvuru anındaki vital değerleri değerlendirildiğinde sistolik tansiyon ortalama değeri $110 \pm 23,0$ $\mathrm{mmHg}$, diyastolik tansiyon ortalama değeri $65,5 \pm 12,3$ $\mathrm{mmHg}$, ortalama nabız sayıs $88 \pm 17,7 / \mathrm{dk}$ olarak saptandı. Hastaların \%27,3'ünde (n: 82) taşikardi, \%9,3'ünde (n:28) hipotansiyon, \%6,3'ünde (n:19) şok tablosu saptandı. Hastaların \%18,3'ünde (n:55) ise normal vital bulgular saptandi. Hemoglobin (Hgb) ve hematokrit $(\mathrm{Htc})$ değerleri incelendiğinde ortalama değerler sırasıyla $9,4 \pm 2,5 \mathrm{gr} / \mathrm{dl}$ ve $\% 28,5 \pm 7,4$ olarak saptand1.
Hastaların endoskopik bulguları Şekil-1'de verildi. Hastalar endoskopik bulgular açısından değerlendirildiğinde $\% 43,4$ 'ünde (n:130) peptik ülser (\%24,7'sinde duodenal ülser; \%18,7'sinde mide ülseri), \%28'inde (n:84) gastroözofagial varis, \%9'unda (n:27) gastrit, \%7,7'sinde (n:23) özofajit/özofagus ülseri, \%5,7'sinde (n:17) malign ülser ya da kitle, \%2'sinde (n:6) Mallory-Weis yırtığı, \%1,7'sinde (n:5) anjiodisplazi, \%1,3'ünde (n:4) ise diğer endoskopik bulgular (divertikül, vs.) saptandı. Peptik ülseri saptanan 131 olgunun Forrest Sınıflaması değerlendirildiğinde olguların $\% 8,3$ 'ü (n:11) evre $1 \mathrm{~B} ; \% 6,1^{\prime} \mathrm{i}$ (n:8) evre 2A; \%16,7'si (n:22) evre 2B; \%7,6's1 (n:10) evre 2C ve \%61'i (n:80) evre 3 olarak saptand1.
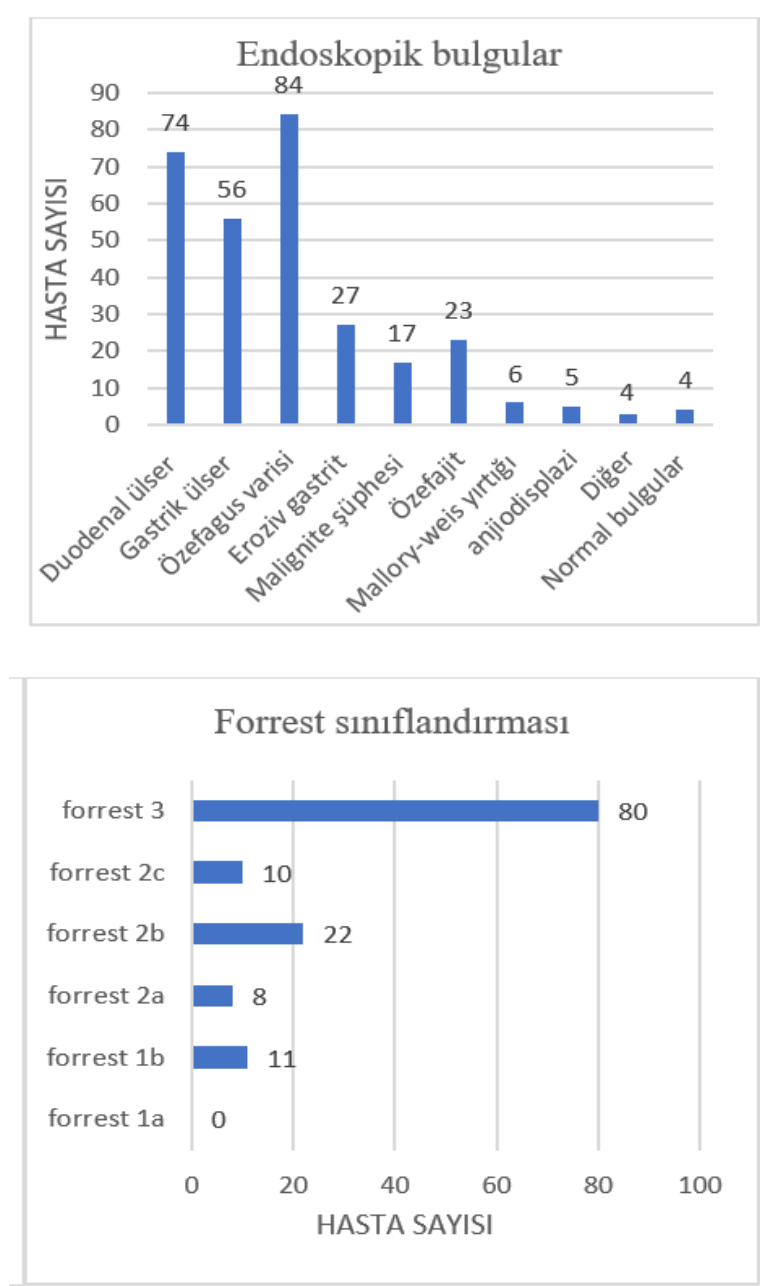

Şekil 1:

Üst gastrointestinal sistem kanamast olan hastaların endoskopik bulguları

Hastaların 82,3'üne (n:247) eritrosit süspansiyon (ES) transfüzyonu yapıldığı saptandı. Medyan ES transfüzyon sayıs1 2 ünite (min:0, max:14) olarak bulundu. Hastaların \%72,3'üne (n:217) 1-5 ünite; \%10'una (n:30) 6 ve daha fazla ES replasmanı yapıldığı saptandi. 
Hastaların medyan yatış süresi 4 gün (min:0, max:42) olarak bulundu. Hastaların \%29,3’ü (n:88) 1-5 gün arasında, \%22,7'si (n:68) 6-10 gün arasında, \%14,7'si (n:44) 10 günden fazla süre hastanede yatırılarak tedavi edildiği saptandı. Olguların \%95'i (n: 285) şifa ile taburcu olurken, \%5'i (n:15) vefat etmiştir.

\section{Tartışma ve Sonuç}

Üst GİS kanama en sık acile başvuru şikayetlerinden biridir. Bu hastaların uygun bir şekilde tedavisi morbidite ve mortaliteyi en aza indirmek için gereklidir. Üst GİS kanama tedavisinde teknolojik gelişmelere bağlı olarak son y1llarda daha etkin tedaviler uygulanmaktadır. Bu nedenle etyopatogenezde rol oynayan faktörlerin iyi tanımlanması tedavi seçiminde önemli bir yer tutmaktadır. Bu çalışmanın amacı kliniğimize üst GİS kanama şikâyeti ile başvuran hastaların demografik ve klinik özelliklerini değerlendirmektir.

Son yapılan çalışmalar incelendiğinde üst GİS kanama ile başvuran hastaların ortalama yaşı 50-70 yaş arasında olmakla birlikte ileri yaşta daha sık görülmektedir ${ }^{6-}$ 8. 2018 yılında Amerika'da yapılan retrospektif bir çalışmada hastaların \%58'inin yaşı 65 yaşın üzerinde ve \%55'i erkek olarak saptanmıştır ${ }^{9}$. Çalışmamızdaki hastaların yaş ortalaması ve cinsiyet dağılımları literatürdeki çalışmalarla uyumlu saptandı. Yapılan çalışmalarda üst GİS kanaması olan hastaların en sık başvuru şikâyeti olarak melena saptanmıştır ${ }^{6,10}$. Çalışmamizda da en sık hastaneye başvuru nedeni melena iken ikinci sıklıkla başvuru nedeni melena ile birlikte olan hematamezdi.

NSAIII, ASA, steroid ve oral antikoagulan gibi ilaçların kullanımı üst GIS kanaması etiyolojisinde önemli bir yer teşkil etmektedir. İleri yaş ile birlikte ASA, NSAIII ve buna benzer ilaçların verildiği hastalıkların sıklığının artması, üst GİS kanama sıklığını arttıran en önemli etkenlerin başında gelmektedir ${ }^{11,12}$. Çalışmamızda hastaların yarısından fazlası sayılan ilaçlardan kullanmaktaydı. Üst GİS kanaması ile ilgili yapılan çalışmalar değerlendirildiği zaman kanamaya eğilim yaratan ilaç kullanımı bizim çalışmamızdakine benzer oranda bulunmuştur ${ }^{2,6}$.

Üst GISS kanaması olan hastalarda başvuru anındaki laboratuvar testleri değerlendirildiğinde anemiye s1k rastlanılmaktadır. Son yapılan çalışmalarda üst GISS kanaması ile başvuran hastaların ortalama hemoglobin değeri $10 \mathrm{~g} / \mathrm{dl}$ 'nin altında bulunmuştur ${ }^{13,14}$. Çalışmamızdaki hastaların başvuru hemoglobin değeri literatürdeki yayınlara benzer şekilde $10 \mathrm{~g} / \mathrm{dl}$ 'nin altında bulunmuştur. Önceki çalışmalara bakıldığında ise yurt dışında üst GİS kanaması nedeniyle yatırılarak tedavi edilen hastaların \%33-53’üne transfüzyon yapıldığı; Türkiye'de yapılan bir çalışmada ise $\% 75$ oranında transfüzyon gereksinimi olduğu görülmüştür ${ }^{2,13,14}$. Çalışmamızda hastaların \%82,3'üne ES transfüzyonu yapılmıştır. Transfüzyon oranlarımızın yüksek olmasının sebebinin, hastanemizin üçüncü basamak bir sevk hastanesi olması ve gelen vakaların komorbid durumlarının fazlalığı ve klinik durumlarının daha ciddi olması ile ilişkili olduğu düşünüldü.

ÖGD, üst GİS kanamasında en etkili tanı ve tedavi yöntemlerinin başında gelmektedir. Literatüre bakıldığında üst GíS kanamasının en sık nedeninin peptik ülser olduğu görülmektedir ${ }^{8,9,15,16}$. Çalışmamızda da literatüre benzer şekilde üst GİS kanamasının en sık nedeni peptik ülser olarak saptanırken, malignite ve varis kanamasının literatürde görüldüğünden daha fazla oranda görüldüğü saptanmıştır. Bu durum üçüncü basamak sevk hastanesi olmamız nedeniyle tarafimıza yönlendirilen vakaların daha komplike olması ile açıklanabilir. ÖGD, üst GİS kanamalarında lezyonları bulmak ve tanımlamak için yüksek bir duyarlılığa ve özgüllüğe sahiptir. Ek olarak, bir kanama lezyonu belirlendikten sonra, terapötik endoskopi akut hemostaz sağlayabilir ve çoğu hastada tekrarlayan kanamayı önleyebilir. Akut üst GİS kanaması olan çoğu hasta için erken endoskopi (24 saat içinde) önerilmekle birlikte, erken endoskopinin mortalite ve morbidite üzerine etkileri tam olarak aydınlatılamamıștır ${ }^{17,18}$. Çalışmamızda literatür ile uyumlu olarak hastaların \%68,3 (n:205)'üne ilk 24 saatte endoskopi yapılmiştır.

Üst GİS kanama tanısıyla hastaneye yatırılan vakaların klinik durumunun şiddeti, ek hastalık varlığı, uygulanan tedaviler, ülkelerin sağlık sistemleri gibi nedenler yatış sürelerini etkileyebilmektedir. Son yapılan çalışmalarda hastaların hastanedeki yatış süreleri ortalama 4-6 gün olmakla birlikte hastaların eşlik eden komorbid durumlarına bağlı olarak farklılıklar göstermektedir $^{6,19}$. Çalışmamızda ortalama yatış süresi 5,3 gün saptanmış olup literatürdeki diğer çalışmalarla benzerlik göstermektedir. Akut üst GİS kanaması en s1k görülen mortalite ve morbidite nedenlerinden olup son yıllarda geliştirilen tanı ve tedavi yöntemlerine rağmen mortalite oranı \% 2-10 civarında seyreden acil bir tıbbi durumdur ${ }^{1,7}$. Çalışmamızdaki hastaların mortalite oranı \%5 (n:15)'dir.

Sonuç olarak, üst GİS kanamaları teknolojik gelişmelere rağmen mortalitesi yüksek acil bir durumdur. Bu çalışmada peptik ülser, üst GİS kanamalarının en sik sebebi olarak bulundu. İleri yaş, NSAIII ve ASA kullanımı üst GİS kanama gelişiminde önemli risk faktörleri olarak saptanmıştır. Özellikle ileri yaş ve ek hastalık nedeniyle NSAIII ve ASA kullanan riskli hastalarda GİS kanama açısından dikkatli olunmalı ve gerekli durumlarda gastroprotetktif tedavi verilmelidir.

Etik Kurul Onay Bilgisi:

Onaylayan Kurul: Uludağ Üniversitesi Tıp Fakültesi Klinik

Araștırmalar Etik Kurulu.

Onay Tarihi: 20.02 .2018

Karar No: 2018 - 04/26 


\section{Üst Gastrointestinal Sistem Kanaması}

\section{Kaynaklar}

1. Tham J, Stanley A. Clinical utility of pre-endoscopy risk scores in upper gastrointestinal bleeding. Expert Rev Gastroenterol Hepatol 2019;13(12):1161-7.

2. Hearnshaw SA, Logan RFA, Lowe D, Travis SPL, Murphy MF, Palmer KR. Acute upper gastrointestinal bleeding in the UK: patient characteristics, diagnoses and outcomes in the 2007 UK audit. Gut 2011;60(10):1327-35.

3. Dutta AK, Chacko A, Balekuduru A, Sahu MK, Gangadharan SK. Time trends in epidemiology of peptic ulcer disease in India over two decades. Indian J Gastroenterol 2012;31(3):111-5.

4. Cappell MS, Friedel D. Initial management of acute upper gastrointestinal bleeding: from initial evaluation up to gastrointestinal endoscopy. Med Clin North Am 2008;92(3):491-509, xi.

5. Barkun AN, Almadi M, Kuipers EJ, et al. Management of Nonvariceal Upper Gastrointestinal Bleeding: Guideline Recommendations From the International Consensus Group. Annals of Internal Medicine 2019;171(11):805-22.

6. Okutur SK, Alkim C, Bes C, et al. Akut üst gastrointestinal sistem kanamaları: 230 olgunun analizi. Akademik Gastroenteroloji Dergisi 2007;6(1):30-6.

7. Robertson M, Majumdar A, Boyapati R, et al. Risk stratification in acute upper GI bleeding: comparison of the AIMS65 score with the Glasgow-Blatchford and Rockall scoring systems. Gastrointest Endosc 2016;83(6):1151-60.

8. Zaltman C, Souza HSP de, Castro MEC, Sobral M de FS, Dias PCP, Lemos V. Upper gastrointestinal bleeding in a Brazilian hospital: a retrospective study of endoscopic records. Arq Gastroenterol 2002;39(2):74-80.

9. Wuerth BA, Rockey DC. Changing Epidemiology of Upper Gastrointestinal Hemorrhage in the Last Decade: A Nationwide Analysis. Dig Dis Sci 2018;63(5):1286-93.
10. Boonpongmanee S, Fleischer DE, Pezzullo JC, et al. The frequency of peptic ulcer as a cause of upper-GI bleeding is exaggerated. Gastrointest Endosc 2004;59(7):788-94.

11. Gralnek IM, Dumonceau J-M, Kuipers EJ, et al. Diagnosis and management of nonvariceal upper gastrointestinal hemorrhage: European Society of Gastrointestinal Endoscopy (ESGE) Guideline. Endoscopy 2015;47(10):a1-46.

12. Gürel S, İmadoğlu O. Varis ve Malignite Dışı Üst Gastrointestinal Sistem Kanamalarının Değerlendirilmesi. Uludağ Üniversitesi Tıp Fakültesi Dergisi 2004;30(2):87-91.

13. Restellini S, Kherad O, Jairath V, Martel M, Barkun AN. Red blood cell transfusion is associated with increased rebleeding in patients with nonvariceal upper gastrointestinal bleeding. Aliment Pharmacol Ther 2013;37(3):316-22.

14. Gencay M, Mavis O, Ozgur R, Ozsiginan ZT, Arici G. Analysis of 148 Cases with Upper Gastrointestinal Bleeding. Okmeydani Medical Journal 2011;27(3):130-7.

15. Stanley AJ, Laine L, Dalton HR, et al. Comparison of risk scoring systems for patients presenting with upper gastrointestinal bleeding: international multicentre prospective study. BMJ [Internet] 2017 [cited 2020 May 1];356. Available from: https://www.bmj.com/content/356/bmj.i6432

16. Wang C-H, Chen Y-W, Young Y-R, Yang C-J, Chen I-C. A prospective comparison of 3 scoring systems in upper gastrointestinal bleeding. Am J Emerg Med 2013;31(5):775-8

17. Sarin N, Monga N, Adams PC. Time to endoscopy and outcomes in upper gastrointestinal bleeding. Can J Gastroenterol 2009;23(7):489-93.

18. Lau JYW, Yu Y, Tang RSY, et al. Timing of Endoscopy for Acute Upper Gastrointestinal Bleeding. N Engl J Med 2020;382(14):1299-308.

19. Kim JJ, Sheibani S, Park S, Buxbaum J, Laine L. Causes of bleeding and outcomes in patients hospitalized with upper gastrointestinal bleeding. J Clin Gastroenterol 2014;48(2):113-8. 
